\title{
PENGARUH ORIENTASI BANGUNAN KANTOR DENGAN RAK CAHAYA GANDA TERHADAP EFISIENSI DISTRIBUSI SUHU UDARA EFEKTIF DAN CAHAYA ALAM
}

\author{
Eddy Indarto*) \\ *)Departemen Arsitektur, Fakultas Teknik, Universitas Diponegoro
}

\begin{abstract}
Rak cahaya adalah salah satu system pengembangan cahaya siang hari dalam membantu meningkatkan distribusi kuantitas pencahayaan di dalam ruangan yang efektif, dan berkontribusi dalam penghematan energi. Selain itu, rak cahaya membantu untuk mengurangi pencemaran lingkungan yang disebabkan oleh penggunaan penerangan buatan yang sumber energinya berasal dari pembakaran fosil, dan meminimalkan ketidaknyamanan visual secara psikologis dan terutama fisiologis yang disebabkan oleh penggunaan pencahayaan buatan pada siang hari. Bangunan kantor sebagai karya arsitektur yang responsive terhadap lingkungan, penting untuk mengambil keuntungan pemanfaatan cahaya alami pada siang hari.Memang dalam desain arsitektur telah banyak dilakukan strategi daylighting klasik menggunakan Light-shelf, akan tetapi penelitian-penelitian yang ada hanya terkain dengan distribusi cahaya dengan rak cahaya tunggal pada letak astronomis tertentu. Dalam penelitian ini ingin mengetahui efektifitas penggunaan rak cahaya ganda untuk delapan orientasi, tidak saja efektifitas distribusi cahaya akan tetapi juga terhadap suhu efektif ruangan, pada bangunan kantor untuk kota-kota dengan letak astronomis 60 Lintang Selatan. Penelitian ini termasuk dalam metode penelitian eksperimental (Groat \& Wang, 2002). Penelitian ini merupakan kajian/review secara kuantitatif tentang penggunaan rak cahaya ganda (double light shelf) pada ruang kantor tipe medium, untuk berbagai orientasi, pengaruhnya terhadap efisiensi distribusi cahaya alami dan suhu efektif ruangan.
\end{abstract}

Keywords: efektifitas distribusi cahaya alam (daylighting), dan menurunkan suhu ruangan

\begin{abstract}
A. Latar belakang
Pada saai ini dunia baru memberi perhatian pada meningkatnya emisi karbon, pemanasan global, dan desain yang berkelanjutan. Penggunaan cahaya alami yang direncanakan pada bangunan non-hunian telah menjadi strategi penting untuk meningkatkan efisiensi energi dengan meminimalkan pencahayaan buatan pada siang hari, dan upaya mengurangi beban pendinginan. Pengenalan strategi dan sistem penerangan alami secara inovatif dapat mengurangi konsumsi listrik bangunan dan juga secara signifikan meningkatkan kualitas cahaya di dalam ruangan.

Cahaya siang hari memberikan iluminasi tinggi dan memungkinkan diskriminasi warna dan rendering warna yang sangat baik, terutama untuk ruang kerja perkantoran. Dua sifat ini berarti cahaya siang hari memberikan kondisi untuk penglihatan yang baik. Namun, cahaya siang hari juga bisa menghasilkan cahaya silau yang tidak nyaman dan refleksi luminasi tinggi pada layar display, keduanya sangat mengganggu penglihatan yang baik. Dengan demikian, efek cahaya siang hari terhadap kinerja bergantung pada bagaimana cahaya siang hari didistribusikan. Semua faktor ini perlu
\end{abstract}

diperhatikan dalam strategi desain penerangan alam untuk bangunan (Ruck, 2010)

Chae, 2014, mengatakan bahwa, rak cahaya (light shelf) adalah perangkat kontrol cahaya yang dapat menghemat energi dari pengurangan penggunaan penerangan buatan pada siang hari, dan memperbaiki lingkungan visual saat distribusi cahaya masuk ke gedung dengan memantulkan cahaya ke langit-langit dalam ruangan. Rak cahaya umumnya menggunakan bahan dengan reflektifitas yang lebih tinggi seperti aluminium atau logam berlapis perak untuk eksterior dan interior jendela samping dan memiliki keunggulan efisiensi baik saat konstruksi maupun dalam pembiayaannya dibandingkan dengan teknologi pencahayaan alami aktif lainnya.

Senada dengan itu, Kurtay, 2016, juga mengungkapkan bahwa, day lighting adalah strategi yang efektif untuk mempertahankan kondisi pencahayaan ruangan dalam yang nyaman dan kesempatan untuk penghematan energi yang besar pada sebuah bangunan 


\section{B. MATERI}

Pemanfaatan cahaya siang hari bisa dianggap sebagai salah satu faktor utama dalam arsitektur berkelanjutan. Cahaya siang hari merupakan salah satu strategi efektif dalam membangun optimalisasi energi. Dengan menggunakan sistem cahaya siang hari yang dikembangkan, perancangan dapat mengurangi konsumsi listrik bangunan secara signifikan. Ini juga mempengaruhi kualitas pencahayaan dalam ruangan. Menggunakan cahaya siang hari memiliki banyak keuntungan ekonomi dan bio-lingkungan. Konsumsi energi listrik merupakan faktor efektif terpenting dalam emisi karbon bangunan, yang terdiri $30-40$ persen dari total energi yang dikonsumsi di bangunan komersial. Dengan memanfaatkan cahaya siang hari, beban pendinginan dapat menurun secara signifikan. Lemahnya perancangan cahaya alami bangunan dan kualitas udara internal yang tidak tepat menyebabkan pengaruh negatif pada kesehatan. Kualitas cahaya siang hari merupakan salah satu faktor yang sangat penting bagi kinerja (Moazzeni, 2016).

Salah satu upaya untuk memanfaatkan cahaya alam telah banyak dilakukan melalui strategi "daylighting" pada bangunan. Mintorogo (2004) dalam SunWord dan Process Architecture, dan Szokolay (2008), menjelaskan bahwa secara garis besar strategi daylighting yang banyak diaplikasikan yaitu:

1. Light-shelf.

Mengandalkan bidang pemantul untuk memperoleh cahaya alami (Gambar 1)

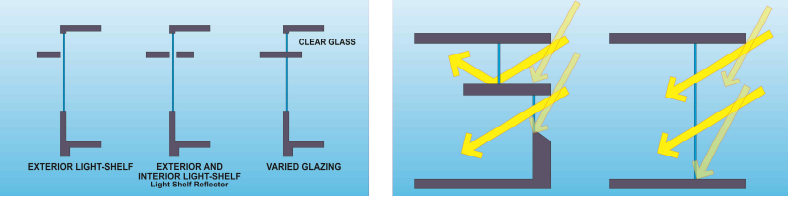

Gambar 1. Berbagai bentuk Light-shelf Sumber: Mintorogo, 2004
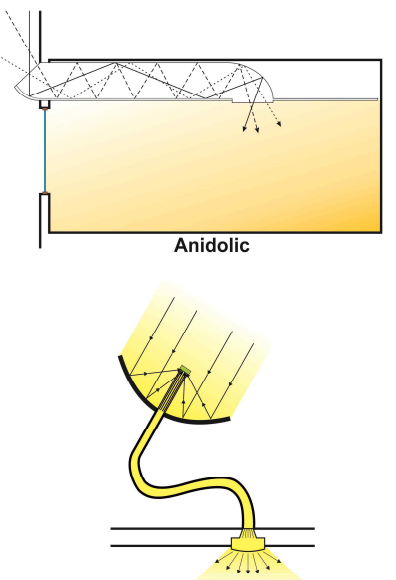

Optical Fibre Lighting

Gambar 2: Reflektor Cahaya

Sumber: diolah dari Szokolay, 2008
2. Strategi teknologi daylighting.

Strategi ini banyak menggunakan reflektor aktif yang secara otomatis dapat mencari datangnya arah sinar matahari, teknologi ini juga dikenal dengan "Heliostat" (Gambar 2)

Hayter (2002) dan Smith (2005) memberi penjelasan bahwa, rak-pemantul cahaya alam (lightshelf) adalah perangkat reflektif, dalam bentuk datar, melengkung, horizontal atau agak menyudut. Elemen ini dapat dipasang di mana saja pada dinding yang fungsinya adalah untuk mengarahkan cahaya alami ke arah langit-langit sekaligus berfungsi sebagai sistem pembayang sinar matahari langsung.

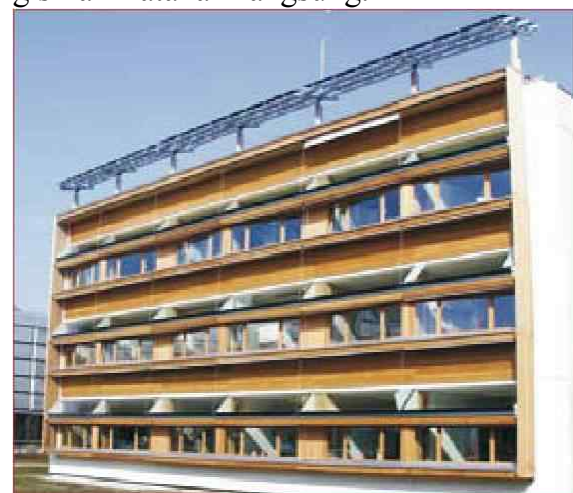

Gambar 3: Sisitem Pemantul Cahaya \& Pembayangan Sumber: Smith, 2005

Cunningham, 2014 memberi penjelasan bahwa, rak pemantul cahaya (light-shelf) adalah perangkat reflektif, dalam bentuk datar, melengkung, horizontal atau agak menyudut. Elemen ini dapat dipasang di mana saja pada dinding yang fungsinya adalah untuk mengarahkan cahaya alami ke arah langit-langit (gambar 5), light-shelf eksternal sekaligus juga dapat berfungsi sebagai sistem pembayang sinar matahari langsung.

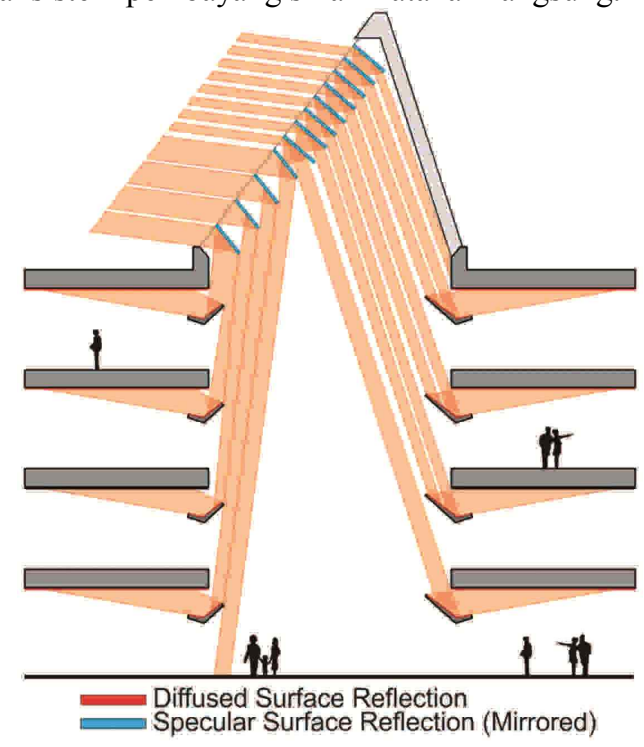


Gambar 5: Berbagai bentuk Internal Light-shelf

Sumber: diolah dari Cunningham, 2014

Hasil penelitian Hossein (2016) tentang rak cahaya (light-shelf) di lingkungan pendidikan Teheran mengungkapkan bahwa, rak cahaya dapat mengurangi silau yang sangat mengganggu kenyamanan visual. Pada siang hari, hasil menunjukkan bahwa rak cahaya dapat efisien mendistribusikan cahaya siang hari (daylight) dan meningkatkan kenyamanan visual.

Pada rak cahaya tunggal yang bagian luar dari elemen rak cahaya dapat diatur sudut kemiringannya, terungkap dari hasil simulasi selama 330 jam menunjukkan orientasi Selatan paling efisien manfaatnya, karena mampu meningkatkan 20\%-40\% kenyamanan visual. Akan tetapi pada orientasi Selatan dengan rak cahaya bagian luar membentuk sudut 300 , (gambar 6) meningkatkan tumpang tindih (overlap) cahaya, sehingga dapat mengganggu kenyamanan visual.

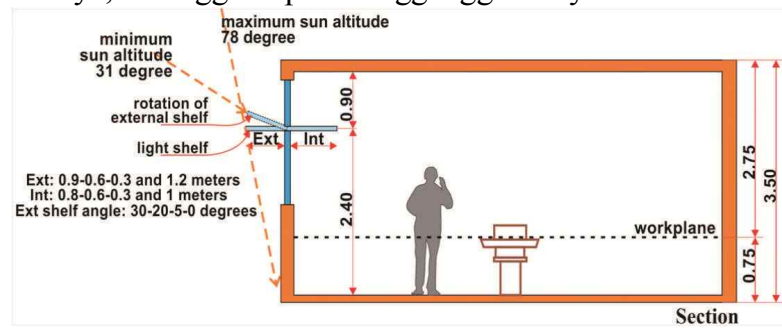

Gambar 6. Strategi Pemanfaatan Cahaya Alami Sumber: diolah dari Hossein, 2016

Kurtay, 2016, meneliti pengaruh garis lintang yang berbeda $\left(0^{\circ}, 15^{\circ}, 30^{\circ}, 45^{\circ}, 60^{\circ}, 75^{\circ}\right)$ terhadap efisiensi rak cahaya untuk 3 perbedaan ketinggian ruang kantor (3m, 3,9 m, 4,8 m ) Hasil penelitian Kurtay ini menunjukkan, efisiensi rak cahaya menurut garis lintang antara $0^{\circ} \& 15^{\circ}$ untuk: 3 ketinggian kantor yang berbeda, terlihat bahwa efisiensi rak cahaya akan menurun dengan meningkatnya ketinggian ruang kantor, dan efisiensi rak cahaya akan meningkat dengan meningkatnya ketinggian ruang kantor pada garis lintang $30^{\circ}, 45^{\circ}, 60^{\circ}$ dan $75^{\circ}$. Nilai efisiensi rak cahaya lebih jelas pada garis lintang tinggi.

Dianjurkan penggunaan rak cahaya pada setiap garis lintang untuk ketinggian kantor $3 \mathrm{~m}$ karena semua nilai efisiensi rak cahaya di atas $5 \%$.

Penggunaan rak cahaya pada lintang $15^{\circ}, 30^{\circ}$ $45^{\circ}, 60^{\circ}, 75^{\circ}$ dianjurkan untuk ketinggian kantor 3,9 $\mathrm{m}$ karena nilai efisiensi rak cahaya di atas $5 \%$.

Penggunaan rak cahaya pada lintang $30^{\circ}, 45^{\circ}$, $60^{\circ}, 75^{\circ}$ disarankan untuk tinggi kantor $4,8 \mathrm{~m}$ karena nilai efisiensi rak cahaya di atas $5 \%$ pada garis lintang ini.

Efek rak cahaya terhadap distribusi cahaya siang hari dapat dipertimbangkan pada garis lintang yang berbeda untuk desain unit perkantoran.
Sesuai hasil penelitian Kurtay, Indonesia terletak diantara garis lintang $0^{\circ} \& 15^{\circ}$, oleh karena itu agar penggunaan rak cahaya efisien, ketinggia ruang kantor adalah $3 \mathrm{~m}$.
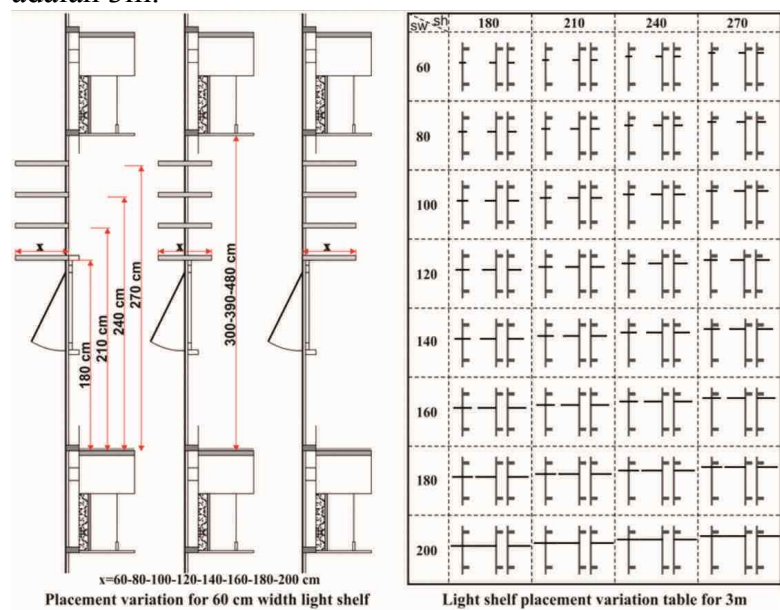

Gambar 7. Varisasi Lebar Dan Posisi Light shelf Sumber: Kurtay (2016)

Panero, 1979, mengatakan tentang garis pandang vertikal untuk penglihatan manusia bahwa, garis pandang biasa dianggap horizontal atau 0O. Garis pandang alami normal atau seseorang berdiri merupakan kerucut sudut pandang sekitar 100 di bawah horizontal dan, jika duduk, sekitar 150 di bawah horizontal.

Objek, yang mengambil 5\% dari kerucut pandang ini $(5 \%$ dari $10 \mathrm{O}=0,5 \mathrm{O})$ hanya akan mengambil sebagian kecil bidang pandang vertikal, dan hanya terlihat saat seseorang memusatkan perhatian secara langsung. Objek yang mengambil sebagian kecil proporsi kerucut pandangan vertikal tidak dominan, dan juga tidak menciptakan perubahan signifikan terhadap lingkungan yang ada, saat objek pendek tersebut ditempatkan di dalam lanskap yang dimodifikasi manusia. Namun, mungkin akan lebih terlihat di lingkungan yang bersih.

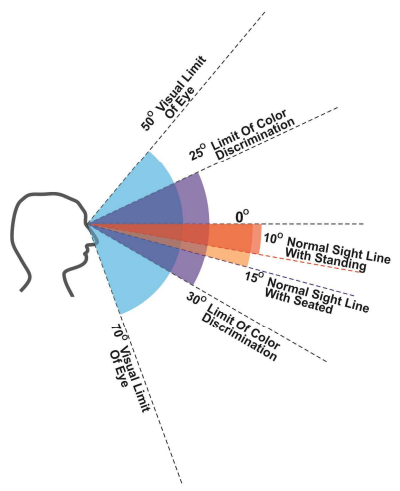

Gambar 8. Vertical Field of View Sumber: diolah dari Panero, 1979 
Dalam beberapatahun terakhir, telah banyak penelitian tentang rak cahaya (light shelf) telah dilakukan, terutama single light shelf yang berkaitan dengan efisiensi pencahayaan alami. Keaslian penelitian ini untuk mengetahui pengaruh penggunaan rak cahaya ganda (double light shelf) dari empat (4) orientasi bangunan, tidak saja terhadap efisiensi terhadap suhu udara efektif ruang kantor akan tetapi juga pengaruhnya pada cahaya alami ruang kantor.

\section{DISKUSI/PEMBAHASAN.}

1. Letak Astronomis dan Orientasi banjgunan

Bangunan sebagai model dalam penelitian ini berupa medium office, secara astronomis terletak pada Lotitude 6,40 Lintang Utara, Longitude 110,3120 Bujur Timur, dan Time Zone $=$ GMT +7 .

Adapun orientasi arah bukaan/jendela atau lubang cahaya, akan disimulasikan untuk menghadap ke: Utara, Timur, Selatan dan Barat

2. Medium Office Sebagai Model Penelitian

Dalam penelitian eksperimentan dengan bantuan Energy Plus dari Open Studio ini, adalah untuk medium office yang rata-rata luasnya adala $6 \mathrm{~m} \times 8 \mathrm{~m}$ dengan ketinggian ruangan $3 \mathrm{~m}$ (gambar 9).

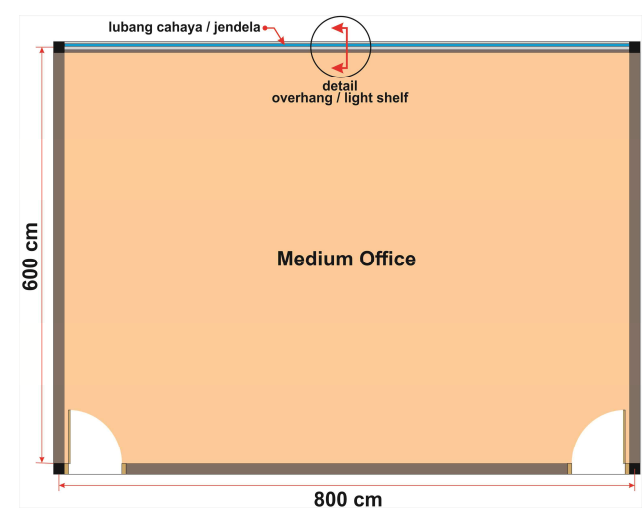

Gambar 9. Denah Medium Office

3. Penentuan overhang dan rak cahaya ganda

Penentuan posisi overhang dan rak cahaya ganda didasari atas ketinggian jandela (lubang cahaya) yang umumnya penentuan ketinggian (di atas lantai) tersebut adalah: ambang bawah $0,8 \mathrm{~m}$ (sedikit diatas bidang kerja untuk office $0,75 \mathrm{~m}$ ), sedangkan ambang atas adalah $2,10 \mathrm{~m}$ (tinggi pinti) ditambah $0,5 \mathrm{~m}$ (biasanya untuk ventilasi atau tambahan lubang cahaya).

Untuk lebar overhang dan rak cahaya (light shelf) ganda yang menjorok keluar harus memperhatikan daerah bebas perangkat bangunan $(0,6 \mathrm{~m})$ sebagai daerah pemeliharaaan/perawatan bangunan (building maintenance zone).

Disamping hal tersebut rancangan overhang dan rak cahaya ganda juga harus memperhatikan garis pandang vertikal (Vertical Field of View) agar pandanga ke luar ruangan tidak terganggu.

a. Posisi Overhang

Dari pertimbangan-pertimbangan tersebut diatas, maka posisi overhang untuk menangkal sinar matahari terletak tepat diatas ambang atas jendela dengan ketinggian 2,6 $\mathrm{m}$ di atas lantai, dengan lebar 0,6 m (gambar 10).

b. Penentuan rak cahaya (light shelf) ganda Light shelf yang dimaksudkan selain untuk menangkal sinarmatahari juga berfungsi sebagai reflektor cahaya matahari ke dalam ruangan, maka posisinya terletak $2,1 \mathrm{~m}$ di atas lantai. Mengacu pada hasil penelitian Kurtay (2016) bahwa, lebar efektif untuk light shelf dengan ketinggian ruang $3 \mathrm{~m}$ adalah $90 \mathrm{~cm}$, maka lebar light shelf pada penelitian ini sama $90 \mathrm{~cm}$, akan tetapi posisinya yang $60 \mathrm{~cm}$ menjorok keluar dan $30 \mathrm{~cm}$ berada dibagian dalam ruangan.

Light shelf ini terletak pada ketinggian 2,1 m diatas lantai sehingga $50 \mathrm{~cm}$ lubang cahaya diatasnya berfungsi agar pantulan sinar matahari dari light shelf dapat masuk ke dalam ruangan (gambar 11).

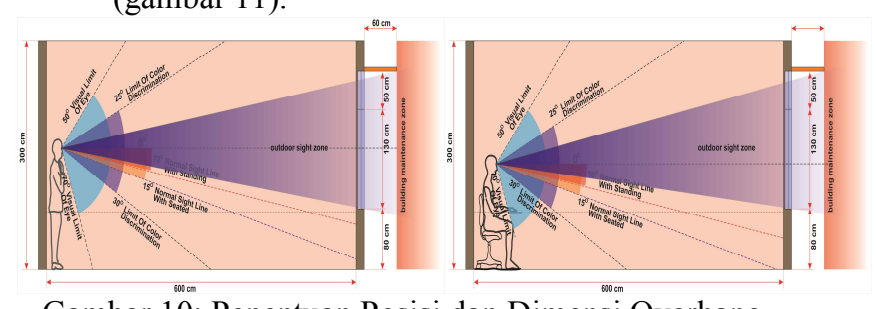

Gambar 10: Penentuan Posisi dan Dimensi Overhang

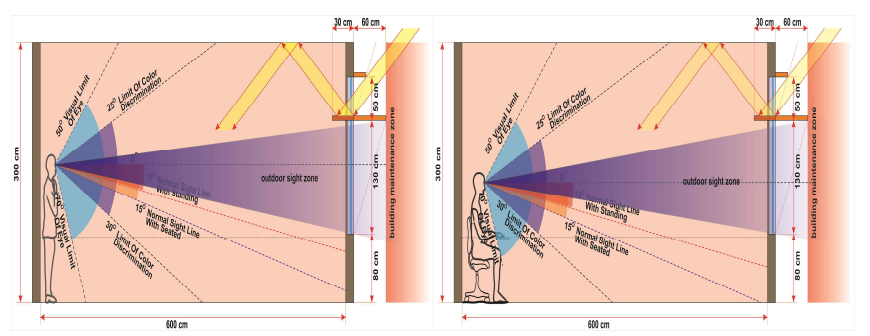

Gambar 11. Penentuan Posisi dan Dimensi Double Light-shelf

4. Validasi Data dengan Hasil Simulasi

Validasi untuk penggunaan Energy Plus dari Open Studio untuk simulasi, baik untuk penerangan alam maupun suhu udara efektif pernah dilakukan pada penelitian sebelumnya ya itu untuk Ruang Dosen FISIP Undip, yang hasilnya adalah sebagai berikut: 


\section{Available online through http://ejournal.undip.ac.id/index.php/modul}

pengaruh orientasi bangunan kantor dengan rak cahaya ganda terhadap efisiensi distribusi suhu udara efektif dan cahaya alam (8pt bold)

Tabel 1: Deviasi Intensitas Cahaya Hasil Pengukuran Di Titik Ukur Utama (TUU) dan Hasil Simulasi Energy+

\begin{tabular}{|c|c|c|c|c|}
\hline Waktu & $\begin{array}{c}\text { Pengukuran } \\
\text { (lux) }\end{array}$ & $\begin{array}{c}\text { Energy + } \\
\text { (lux) }\end{array}$ & $\begin{array}{c}\text { selisih } \\
\text { (lux) }\end{array}$ & Deviasi \\
\hline Jam 7.00 & 1004 & 1050 & 46 & 0,05 \\
\hline Jam 9.00 & 868 & 900 & 32 & 0,04 \\
\hline Jam 12.00 & 1303 & 1350 & 47 & 0,04 \\
\hline Jam 15.00 & 816 & 850 & 34 & 0,04 \\
\hline Jam 17.00 & 458 & 440 & 18 & 0,04 \\
\hline
\end{tabular}

Tabel-1 tersebut diatas menunjukkan bahwa deviasi (penyimpangan) intensitas cahaya antara hasil pengukuran dan hasil Simulasi menggunakan Energy+ tidak lebih dari 5\%. Ini memberikan arti bahwa Simulasi dengan Energy Plus dari Open Studio dapat dilanjutkan untuk analisis Simulasi intensitas cahaya selanjutnya.

Demikian juga dengan Tabel-2, yang menunjukkan bahwa deviasi (penyimpangan) temperatur udara ruang rata-rata antara hasil pengukuran dan hasil Simulasi menggunakan Energy+ tidak lebih dari 5\%. Ini juga memberikan arti bahwa Simulasi dengan Energy Plus dari Open Studio dapat dilanjutkan untuk analisis Simulasi temperatur udara selanjutnya.

Tabel 2: Deviasi Temperatur Udara Ruang Rata-rata Hasil Pengukuran dan Hasil Simulasi Energy+

\begin{tabular}{|c|c|c|c|c|}
\hline Waktu & Pengukuran & Energy + & Selisih & Deviasi \\
\hline Jam 7.00 & 23,11 & 22,6 & 0,51 & 0,02 \\
\hline Jam 9.00 & 26,24 & 25,3 & 0,94 & 0,04 \\
\hline Jam 12.00 & 26,48 & 27,2 & 0,72 & 0,03 \\
\hline Jam 15.00 & 27,26 & 28,4 & 1,14 & 0,04 \\
\hline Jam 17.00 & 28,12 & 28,5 & 0,38 & 0,01 \\
\hline
\end{tabular}

5. Komparasi antara Penggunaan Overhang dan Double Light Shelf

Komparasi antara penggunaan overhang dan double light shelf ini dimaksudkan untuk mengetahui efisiensi penggunaan double light shelf, untuk orientasi Utara, Timur, Selatan, dan Barat, baik pada saat matahari berada di equator (21 Maret dan 23 September), saat matahari berada di titik balik lintang Utara (22 Juni), dan pada saat matahari berada di titik balik lintang Utara (22 Dersember).

\section{a. Orientasi Utara}

Komparasi antara pengaruh penggunaan overhang dan double light shelf pada otientasi Utara (Gambar 12) terhadap temperatur udara efektif memperlihatkan bahwa, untuk tanggal 22 Dersember dan 21 Maret tidak terjadi perbedaan yang signifikan. Perbedaan temberatur udara efektif terjadi hanya pada tanggal 22 Juni, penggunaan double light shelf mengakibatkan temperatur udara efektif sebesar 31,2 OC lebih rendah dibanding penggunaan overhang.

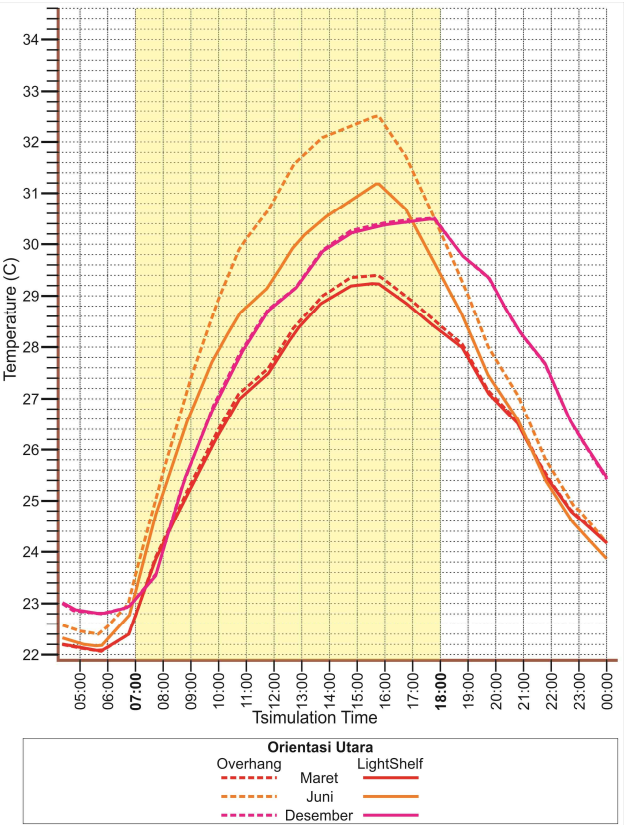

Gambar 12. Komparasi Grafik Suhu Udara Efektif Antara Penggunaan Overhang dan Double Light Shelf Orientasi Utara.

Walaupun demikian, distribusi cahaya alami pada 22 Juni tersebut masih memenuhi persyaratan unruk perkantoran yaitu: light levels dekat dengan jendela mencapai 7.700 Lux dan yang paling jauh (dalam) dari jendela masih sekitar 300 Lux (Gambar 13)

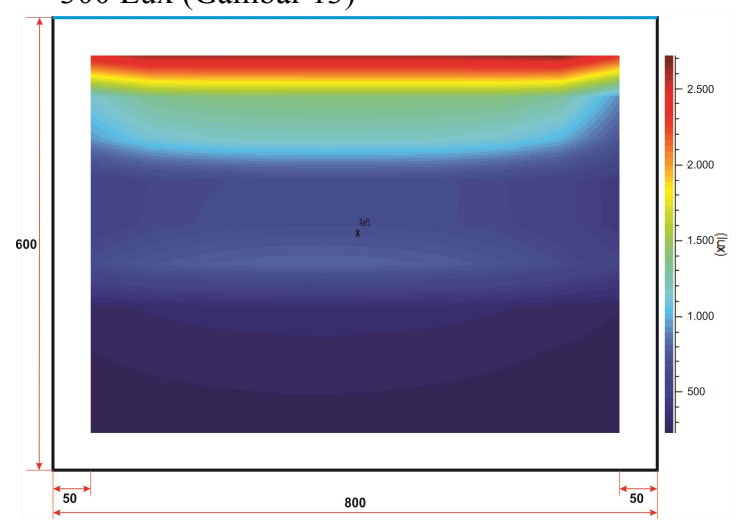

Gambar 13. Distribusi Cahaya Penggunaan Double Light Shelf

Pada 22 Juni Orientasi Utara.

Hasil komparasi ini menunjukkan bahwa untuk orientasi Utara, penggunaan double light shelf lebih efisien.

b. Orientasi Timur

Komparasi antara pengaruh penggunaan overhang dan double light shelf pada otientasi Timur (Gambar 14) terhadap temperatur udara 
efektif memperlihatkan bahwa, baik tanggal 21 Maret, 22 Juni, dan 22 Dersember terjadi perbedaan. Rata-rata dengan menggunakan double light shelf, temperatur udara efektif pada siang hari lebih rendah sekitar 0,6 OC sampai 1,2 OC dibanding penggunaan overhang. Perbadaan tertinggi terjadi pada tanggal 22 Desember jam 10.00 sampai jam 12.00 WIB yaitu antara 0,8 OC $-1,2$ OC.

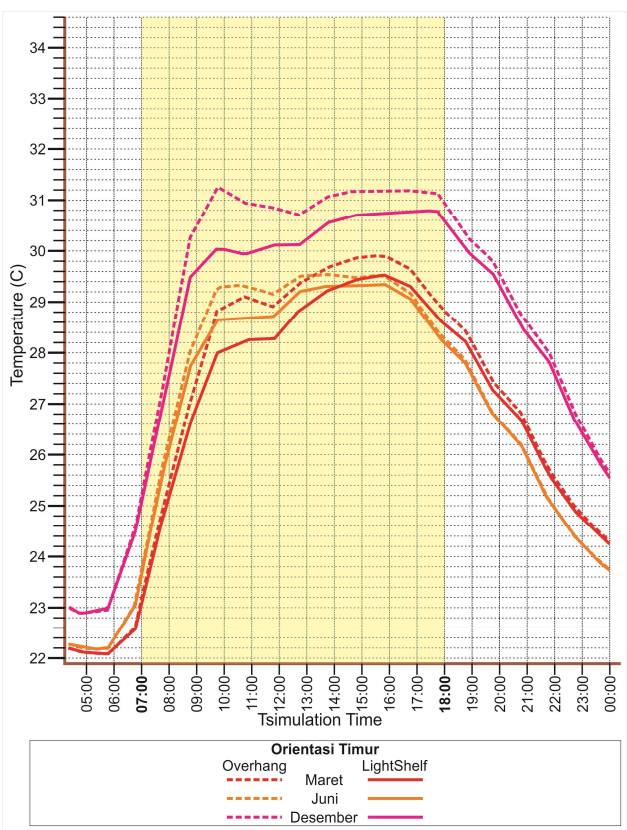

Gambar 14. Komparasi Grafik Suhu Udara Efektif Antara Penggunaan Overhang dan Double Light

Shelf Orientasi Timur.

Hal ini menunjukkan bahwa penggunaan double light shelf untuk orientasi Timur ini sangat efisien terkait dengan penurunan temperatur udara efektif.

Demikian juga dengan distribusi cahaya alami pada 22 (Suhu lebih rendah dibanding tanggal lainnya) distribusi light levels masih memenuhi persyaratan untuk perkantoran, yaitu dekat dengan jendela mencapai 3.000 Lux dan yang paling jauh (dalam) dari jendela masih sekitar 250 Lux (Gambar 15).

Hasil komparasi ini menunjukkan bahwa untuk orientasi Timur, penggunaan double light shelf lebih efisien baik untuk tanggal 21 Maret, 22 Juni, maupun tanggal 22 Dersember.

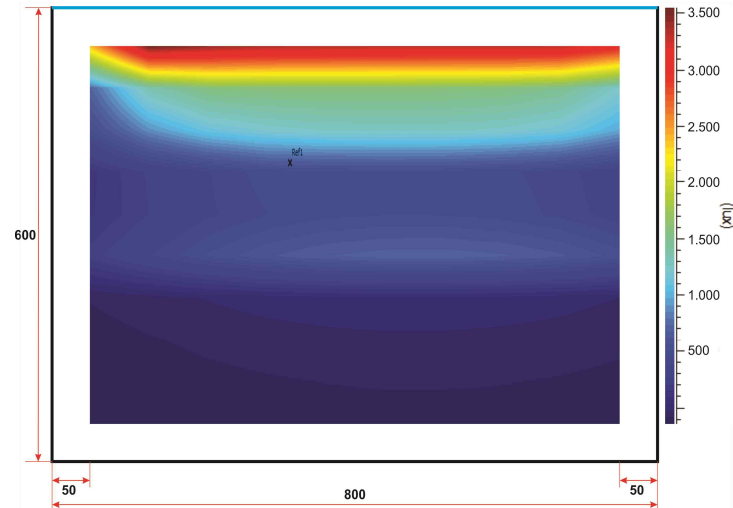

Gambar 15. Distribusi Cahaya Penggunaan Double Light Shelf

Pada 22 Juni Orientasi Utara

c. Orientasi Selatan

Komparasi antara pengaruh penggunaan overhang dan double light shelf pada otientasi Timur (Gambar 16) terhadap temperatur udara efektif memperlihatkan bahwa, tanggal 22 Dersember jam 9.30 temperatur udara efektif dengan penggunaan double light shelf adalah 27,6 OC, lebih rendah 3,6 OC dibanding penggunaan overhang yang mencapai 31,2 OC. Tetapi pada jam 17.00 WIB, temperatur udara efektif dengan penggunaan double light shelf adalah 31,6 OC lebih tinggi 0,6 OC dibanding penggunaan overhang sebesar 31,0 OC

Pada 21 Maret dan 22 Juni, temperatur udara efektif dengan penggunaan double light shelf lebih rendah 0,6 OC dibanding temperatur udara efektif dengan penggunaan overhang.

Secara rata-rata hal ini menunjukkan bahwa penggunaan double light shelf untuk orientasi Selatan ini masih lebih efisien terkait dengan penurunan temperatur udara efektif.

Adapun temperatur udara efektif dengan penggunaan double light shelf pada tanggal 22 Juni merupakan yang terendah dibanding dengan bulan laiinnya. Walaupun demikian distribusi light levels masih memenuhi persyaratan untuk perkantoran, yaitu dekat dengan jendela mencapai 1.800 Lux dan yang paling jauh (dalam) dari jendela masih sekitar 250 Lux (Gambar 17).

Hasil komparasi ini menunjukkan bahwa untuk orientasi Selatan, penggunaan double light shelf lebih efisien terutama untuk tanggal 21 Maret, 22 Juni. 


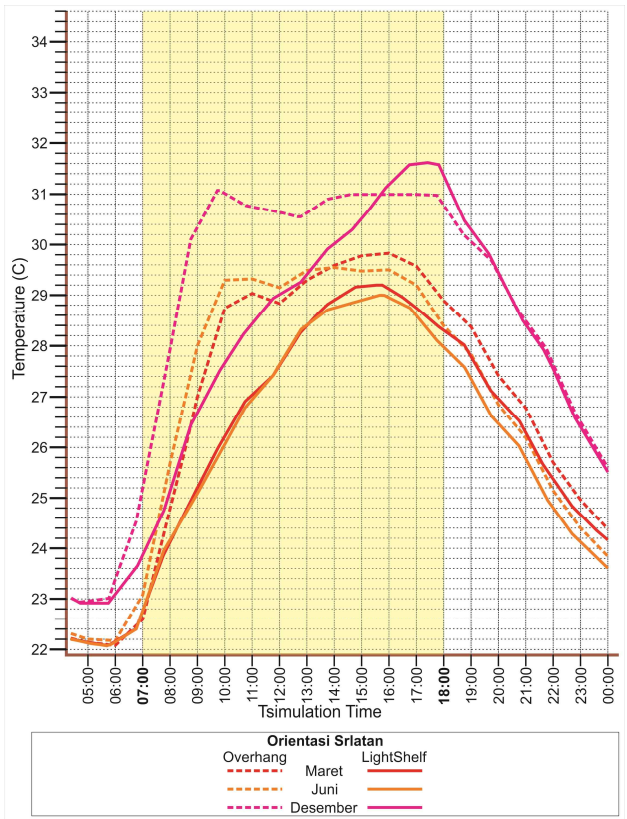

Gambar 16. Komparasi Grafik Suhu Udara Efektif Antara Penggunaan Overhang dan Double Light Shelf Orientasi Selatan.

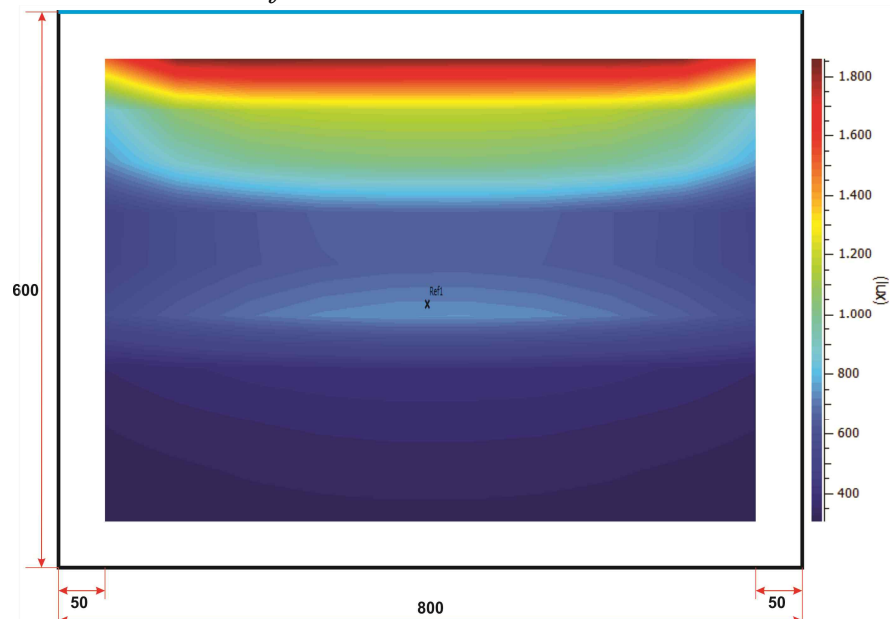

Gambar 17. Distribusi Cahaya Penggunaan Double Light Shelf

Pada 22 Juni Orientasi Selatan.

d. Orientasi Barat.

Komparasi antara pengaruh penggunaan overhang dan double light shelf pada otientasi Barat (Gambar 18) terhadap temperatur udara efektif memperlihatkan bahwa, tanggal 22 Dersember sepanjang hari tidak terjadi perbedaan temperatur udara efektif yang signifikan.

Pada 21 Maret temperatur udara efektif yang menggunakan double light shelf sebesar $31{ }^{\circ} \mathrm{C}$ lebih rendah $0,8{ }^{\mathrm{O}} \mathrm{C}$ dibanding yang menggunakan overhang yaitu $31,8{ }^{\circ} \mathrm{C}$.
Akan tetapi terjadi perbedaan pada tanggal 22 Juni, temperatur udara efektif dengan penggunaan double light shelf sebesar 31,4 OC, justru lebih tinggi 1,6 OC dibanding temperatur udara efektif dengan penggunaan overhang yaitu sebesar 29,8 .

Hasil komparasi ini menunjukkan bahwa untuk orientasi Barat, penggunaan double light shelf hanya lebih efisien untuk tanggal 21 Maret.

Adapun distribusi cahaya alam tanggal 21 Maret untuk orientasi Barat ini memenuhi persyaratan light levels untuk pekerjaan perkantoran, yaitu dekat dengan jendela mencapai 1.800 Lux dan yang paling jauh (dalam) dari jendela masih sekitar 250 Lux (Gambar 19).

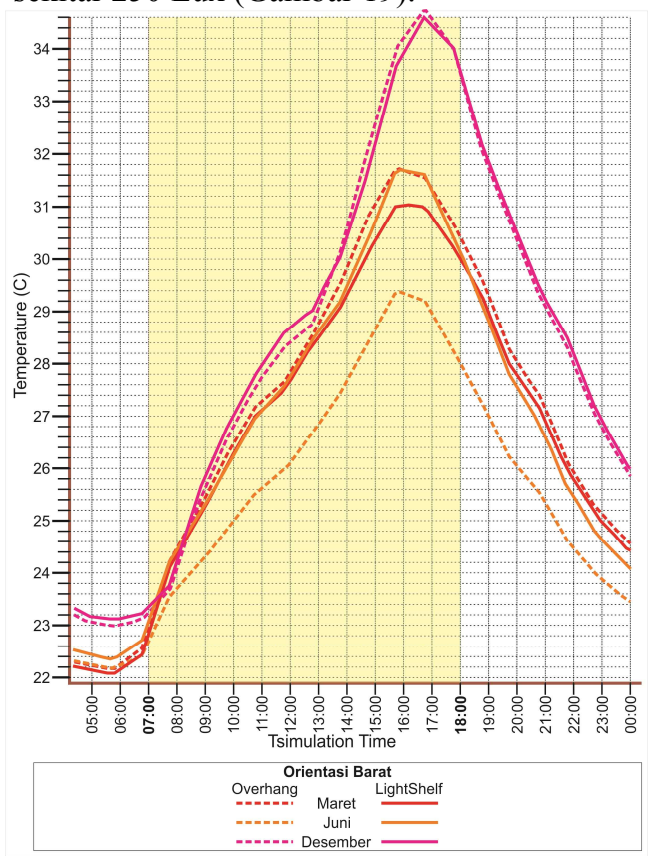

Gambar 18. Komparasi Grafik Suhu Udara Efektif Antara Penggunaan Overhang dan Double Light Shelf Orientasi Barat.

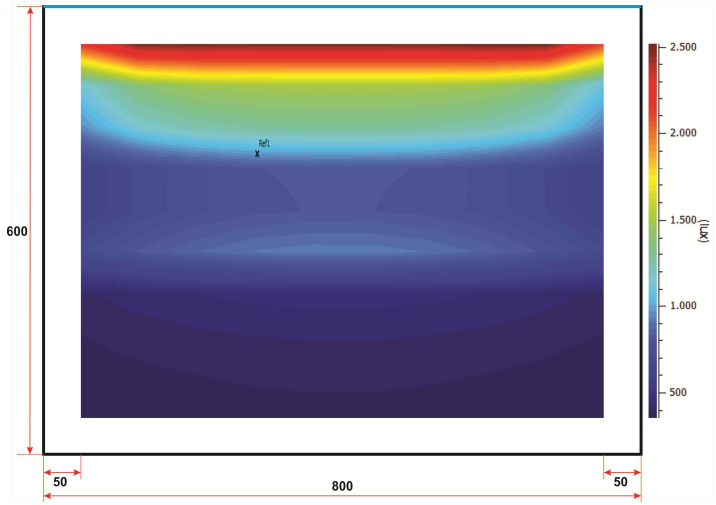

Gambar 19. Distribusi Cahaya Penggunaan Double Light Shelf

Pada 21 Maret Orientasi Barat. 


\section{KESIMPULAN}

Dari hasil analisis komparasi antara pengaruh penggunaan overhang dan double light shelf terhadap temperatur udara efektif dan distribusi cahaya alami, melalui simulasi menggunakan Energy Plus dari Open Studio tersebut diatas, dapat disimpulkan bahwa:

1. Penggunaan double light shelf yang paling efisien adalah untuk orientasi bangunan yang bukaan/jendelanya menghadap ke Timur. Pada orientasi Timur ini temperatur udara efektif yang diakibatkan penggunaan double light shelf lebih rendah jika dibandingkan dengan temperatur udara efektif yang diakibatkan penggunaan overhang, untuk semua posisi matahari.

2. Untuk Orientasi Barat Penggunaan double light shelf tidak efisien karena hanya efisien pada saat posisi matahari di equator saja (tanggal 21 Maret dan 23 September)

\section{E. Ucapan Terima Kasih}

Atas tersusunnya tulisan ini saya mengucapkan terima kasih, khususnya kepada Bapak Jalal Er Riyanto yang telah membantu dalam penyusunan algoritma simulasi, dan kepada Departemen Arsitektur, Fakultas Teknik Undip, serta kepada semua pihak yang telah memberikan bantuan dan dukungan atas terselesaikannya penelitian ini

\section{DAFTAR PUSTAKA}

Chae, Woori. Heangwoo Lee and Yongseong Kim. (2014) A Research on Basic Data for the Design of Combined Light Shelves Depending on Internal Angle. Advanced Science and Technology Letters. Vol.47 (Architecture and Civil Engineering 2014), pp.50-53

Cunningham, Patrick. Paul Zaferiou. Kera Lagios (2014)A Case Study in Reflective Daylighting. Perkins+Will Research Journal/Vol 06.01.2014.

Hayter,Sheila (2002) Shading Strategies, Sustainable Design Guide-The Building Architectural Design. Laboratory Implementation Requirements Chapter 4. LANL (Los Alamos National Laboratory). New Mexico

Hossein, Mohammad Moazzeni. Zahra Ghiabaklou (2016) Investigating the Influence of Light Shelf Geometry Parameters on Daylight Performanceand Visual Comfort, a Case Study of Educational Spacein Tehran, Iran. Multidisciplinary Digital Publishing Institute MDPI,Basel,Switzerland

Kurtay, Cüneyt. Okay Esen (2016) The Efficiency of Light Shelves According to Latitudes in Office Buildings. Gazi University Journal of Science, 29(4):711-721
Mintorogo, Danny Santoso. (2004) The 3 - In - 1 Skylight Shading Device For Surabaya Indonesia : An Energy Saving And Considerations. Dimensi Teknik Arsitektur, Des, Vol.32, p.150

Panero, Julius dan Martin Jelnik (1979) Human Dimension and Interior Space. Whitney Library of Design, The Architectural Press Ltd.

Ruck, Nancy (2010) Daylight in Buildings.International Energy Agency Energy Conservation in Buildings and Community Systems Programme

Satwiko, Prasasto (2009) Fisika Bangunan. Penerbit ANDY Yogyakarta

Smith, Peter F (20050 Architecture in a Climate of Change. Elsevier Ltd, Linacre House, Jordan Hill, Oxford

Szokolay, Steven V (2008) Introduction to Architectural Science -The Basis of Sustainable Design. Architectural Press is an imprint of Elsevier Linacre House, Jordan Hill, Oxford, Burlington 